\title{
The Relationship Between Anthropometrical Domain and Upper Extremity Abnormalities in Primary School Girl Students
}

\author{
Saeed Ilbeigi ${ }^{1}$, Nafiseh Rastegar ${ }^{2}$, Marzieh Saghebjoo ${ }^{1}$, Ahmad Ebrahimi Etri ${ }^{3}$, Hossein Farzaneh ${ }^{2}$
}

1. Associate Professor, Faculty of Sport Sciences, University of Birjand, Birjand, Iran

2. MA in Sport Sciences, Faculty of Sport Sciences, University of Birjand, Birjand, Iran

3. Associate Professor, Faculty of Sport Sciences, Ferdowsi Mashhad University, Mashhad, Iran

\begin{tabular}{ll}
\hline \multicolumn{2}{c}{ Article Info } \\
\hline Original Article \\
\\
Received: & 19 May 2018 \\
Accepted: & 30 June 2018 \\
Published Online & 30 June 2018
\end{tabular}

DOI: $10.30699 /$ jergon.6.1.19

Use your device to scan and read the article online

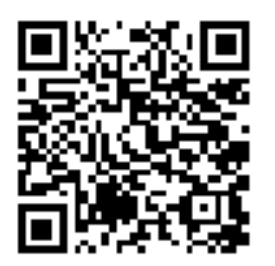

Corresponding Information

\section{Saeed Ilbeigi}

Faculty of Sport Sciences, University of Birjand, Birjand, Iran

Email:silbeigi@birjand.ac.ir

\begin{abstract}
Background: The purpose of this article was to study the relationship between anthropometrical domain and upper body's abnormalities in primary school girl students in Mashhad.

Methods: In this study, 14225 girl students were selected as the statistical population, and then 375 subjects were selected as samples of the study using cluster randomized technic. Some anthropometrical parameters as popliteal height, popliteal-buttock length, elbow height from $90^{\circ}$ angle, and shoulder height from setting position along with some educational dimensions of equipment used such as bench height, bench depth, desk height and width were measured. Moreover, upper body's extremity abnormalities including lumbar lordosis and thorax kyphosis were evaluated by flexible ruler. The related anthropometrical measures along with desk and bench dimensions also were determined in range of accepted limit (AL), over range of accepted limit and below range of accepted limit for each of benches and desks' dimension. For statistical analysis the Chi-Square test in contingency tables, Cramer's phi were used by SPSS16 $(P<0 / 05)$.
\end{abstract}

Results: The result indicated that the 81.8 percent of benches were higher than max accepted limit of the popliteal height. Also 76.8 percent of students used desks that were higher than max accepted limit $(P<0 / 05)$. Bench depth was inappropriate for $\% 100$ of students and smaller than min accepted limit. Furthermore significant relationship was observed between adequate bench height with popliteal height and abnormalities lordosis and kyphosis $(P \leq 0 / 05)$.

Conclusion: The result of present study indicated that educational equipment of Mashhad schools had no minimum ergonomic standard. Some suggestions should be considered to improve the ergonomics of school equipment according to anthropometrical parameters of students.

Keywords: Ergonomic, Anthropometric, Educational Equipment, Upper Extremity Abnormality.

Copyright (C) 2018, Journal of Ergonomics. This is an open-access article distributed under the terms of the Creative Commons Attribution-noncommercial 4.0 International License which permits copy and redistribute the material just in noncommercial usages, provided the original work is properly cited

\footnotetext{
How to Cite This Article:
}

Ilbeigi S, Rastegar N, Saghebjoo M, Ebrahimi Etri A, Farzaneh H. The Relationship Between Anthropometrical Domain and Upper Extremity Abnormalities in Primary School Girl Students. J Ergon. 2018; 6 (1): 19-29 


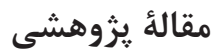

ارتباط بين ابعاد آنترويومتريك با ناهنجارىهاى بالاتنه در دانش آموزان دختر مقطع ابتدايى

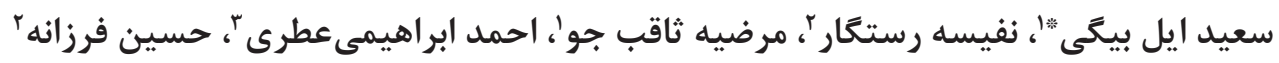

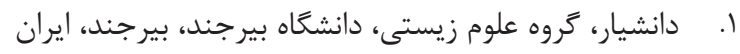

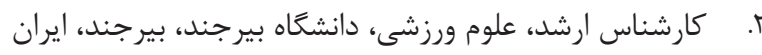

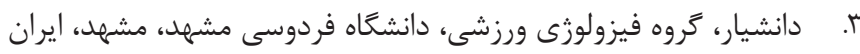

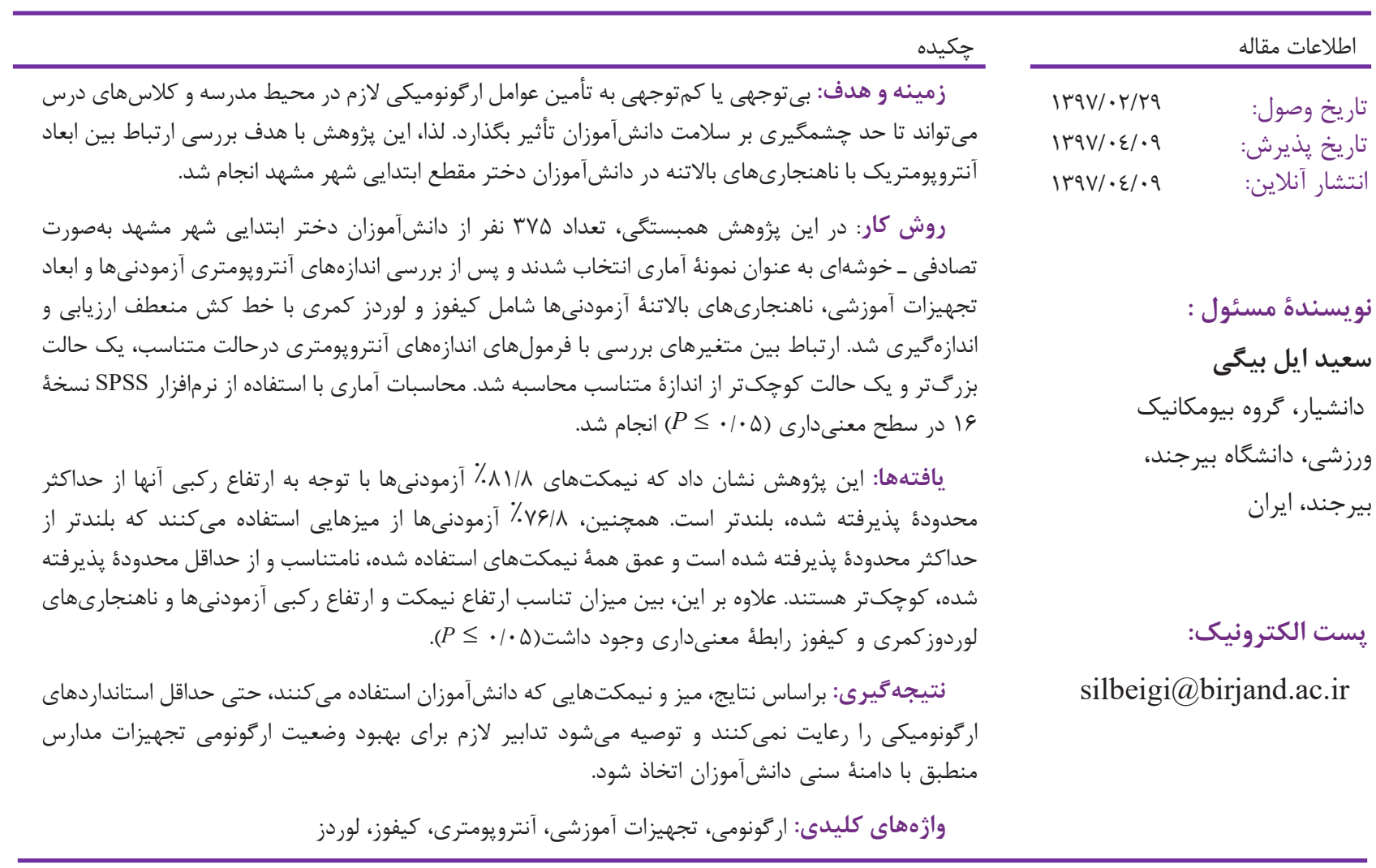

تحمل كنند و آثار منفى فيزيولوزيكى زيادى دارد. ازجمله:

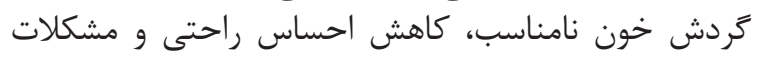

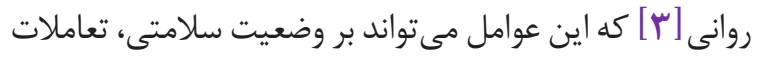

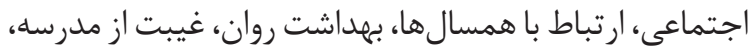

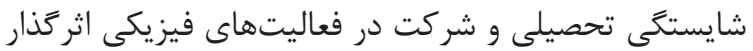

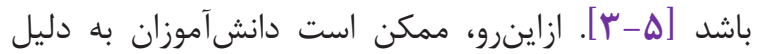

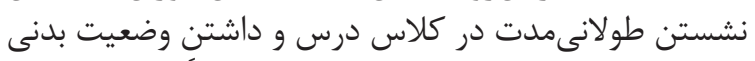

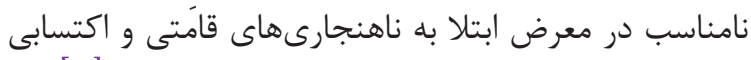

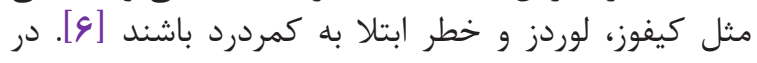

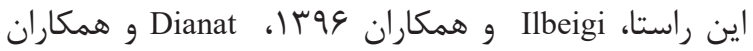

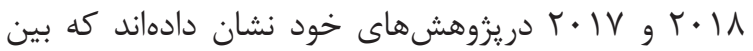

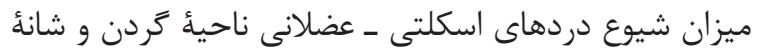

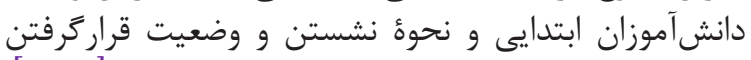

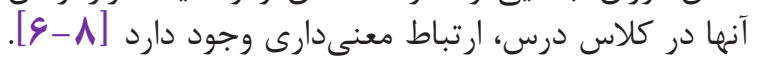
Caneiro

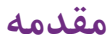

براساس فلسفة اساسى اركَونومى، طراحى ايستخاه كار بايد

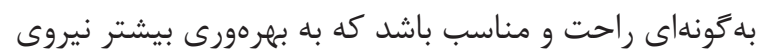

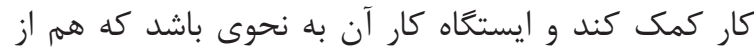

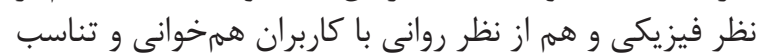

داشته باشد [1].

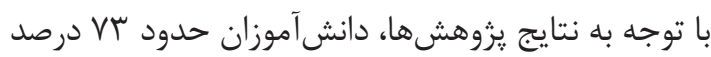

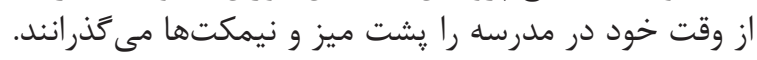

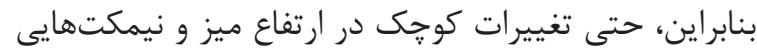

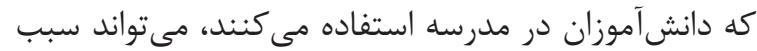

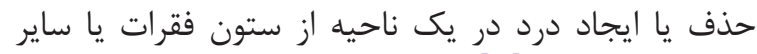

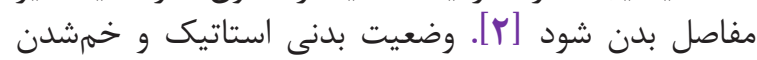

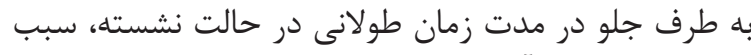

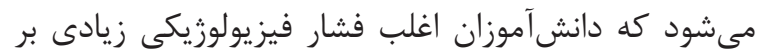

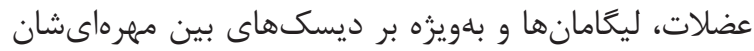


باعث ايجاد يوسجر نامناسب، درد و بروز مشكلات اسكلتى -

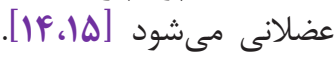

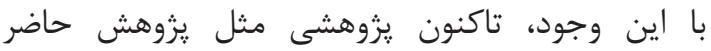

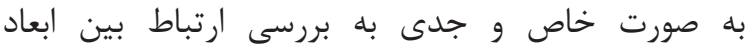

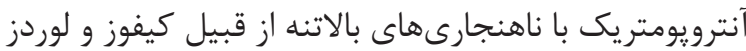

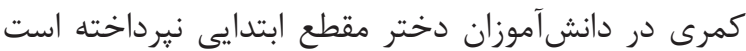

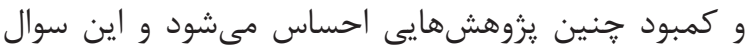

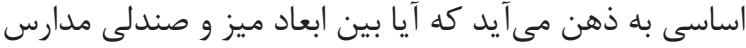

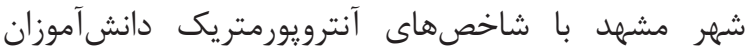

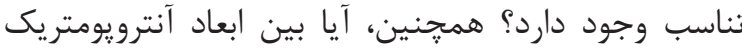

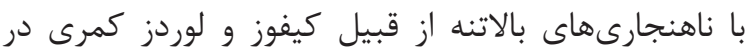

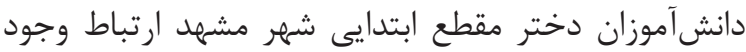

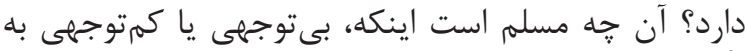

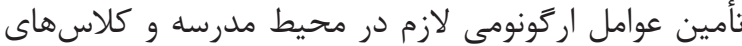

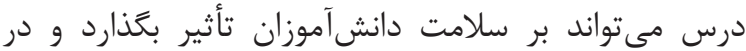

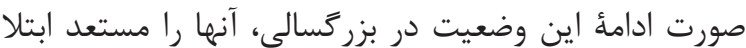

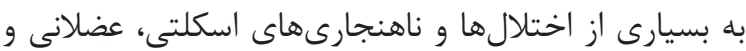

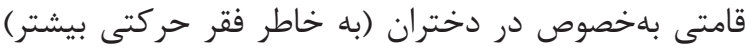

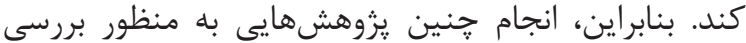

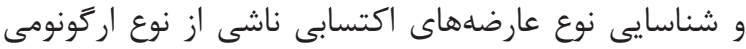

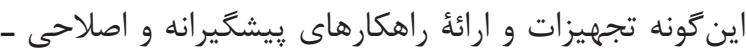

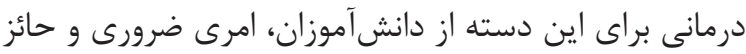

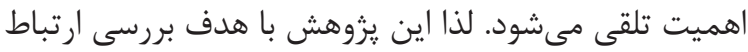

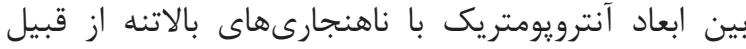

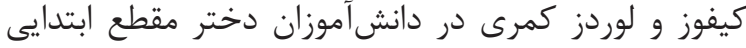

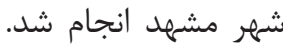

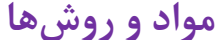

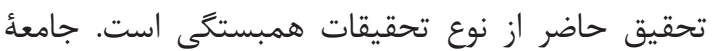

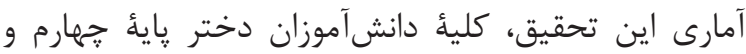

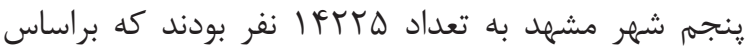

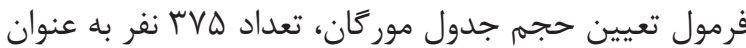

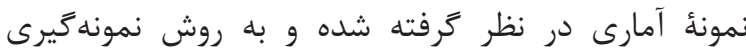

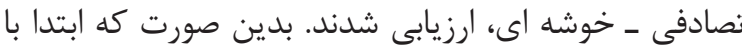

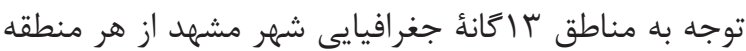

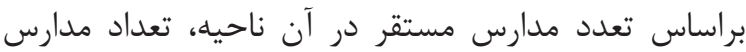

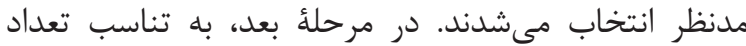

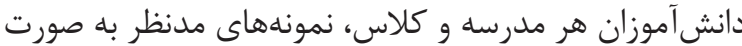

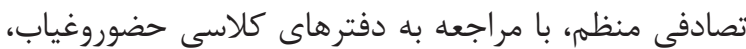

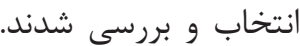

براى جمعآورى اطلاعات، پِ ار از اخذ مجوزهاى مربوطه

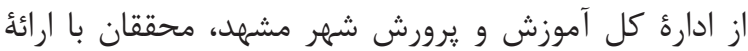

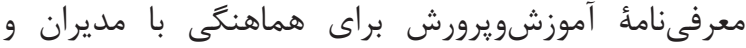

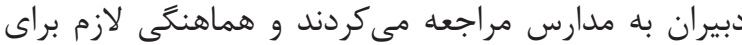

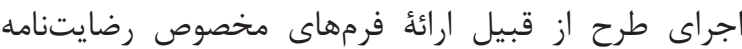

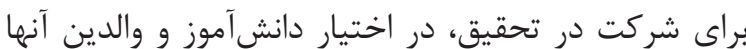

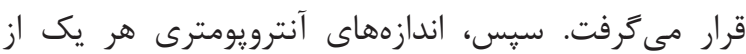

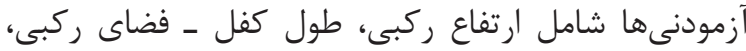

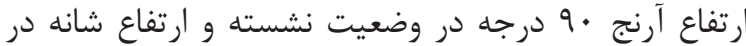

كردند كه وضعيتهاى مختلف نشستن، بر وضعيت كردن ون و و

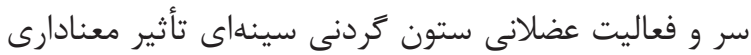

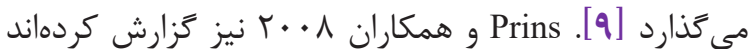

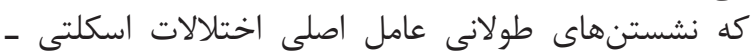

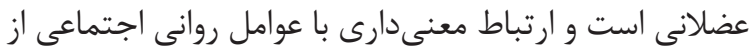

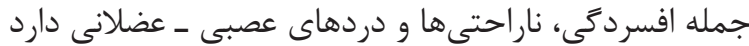

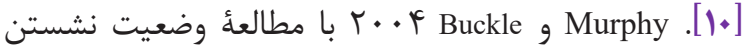
دانشآموزان در كلاس درس نشان دادند كه فئ فعاليت كم

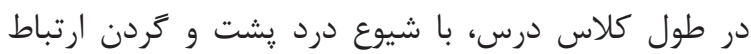

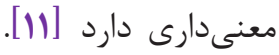

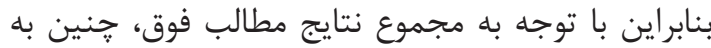
نظر مىرسد كه وضعيت نشستن دانشآمآموزان و و فعاليتهاي

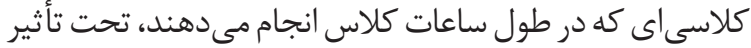

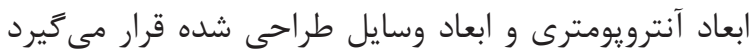

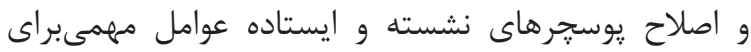

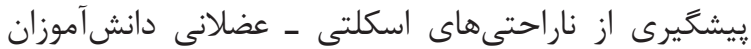

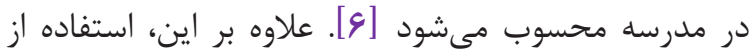

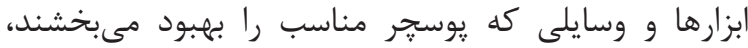

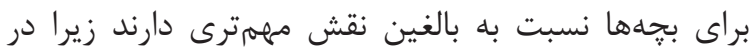

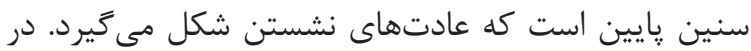

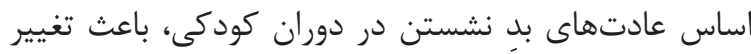

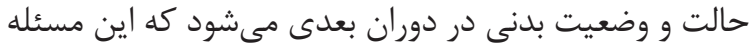

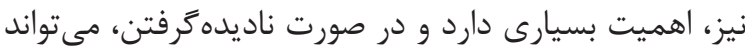

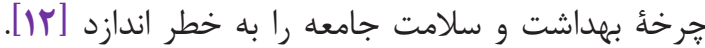
تاكنون درباره ابعاد آنترويومترى دانشآموزان و تناسب

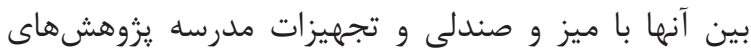

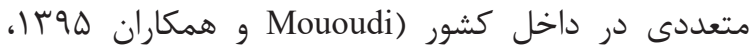
Aghara- ، ان ان

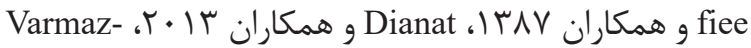
gar

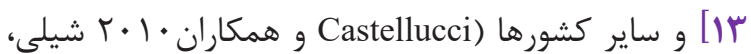
Gouvali

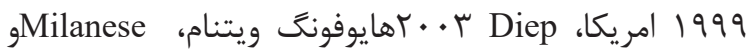
Panagiotopoulou و همكاران r • • r تسالونيكاى يونان، Samuel و همكاران • • • إمريكا)

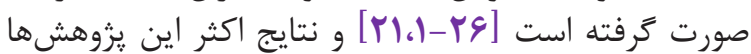

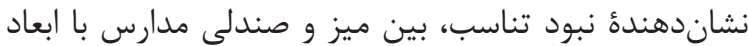

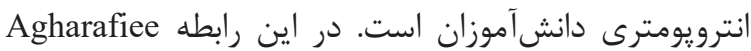

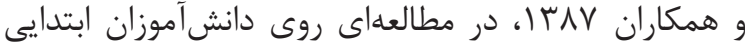

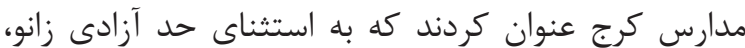

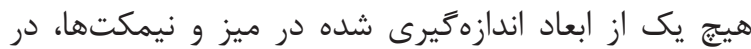

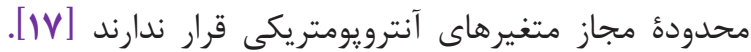

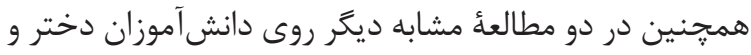

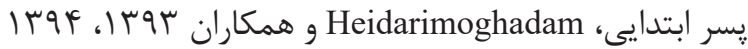

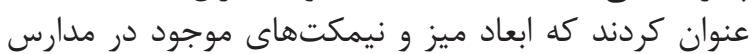
ابتدايى شهر همدان براى اكثر دانشآموزان منان مناسب نيست و دود مدارس 


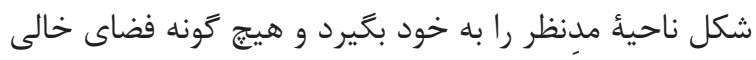

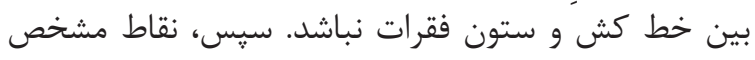

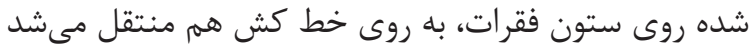

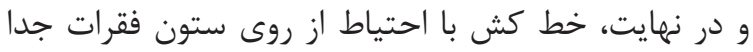

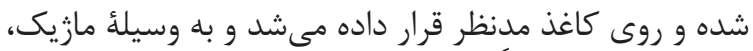

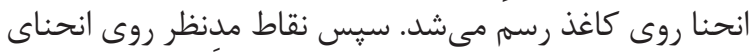

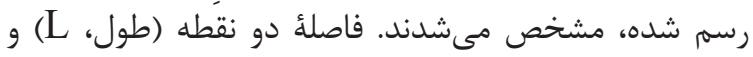

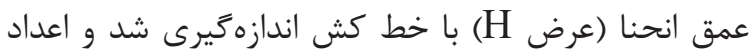

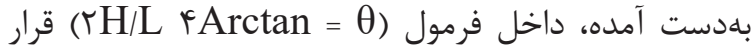

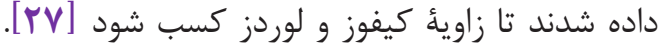

\section{فرمولهاى بررسى تناسب ابعاد اركونومى تجهيزات آموزشى با اندازههاى آنترويومترى تناسب إساد}

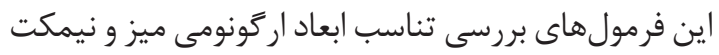

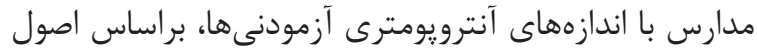

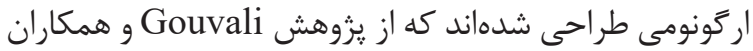

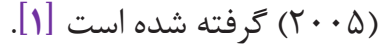

براى تشخيص تناسب ارتفاع ركبى هر آزمودنى با ارتفاع نيمكت از فرمول زير استفاده كرده است:

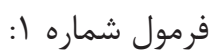

\section{$(\mathrm{P}+2) \cos 30 \leq \mathrm{SH} \leq(\mathrm{P}+2) \cos 5$}

در اين فرمول: P ارتفاع ركبى، SH ارتفاع نشيمنكاه است.

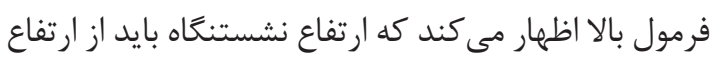
ركبى كمتر باشد، طورى كه:

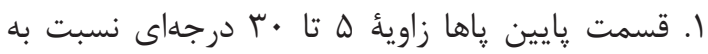
محور عمودى تشكيل دهد.

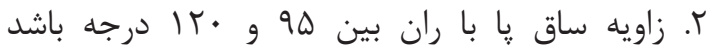

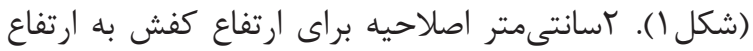

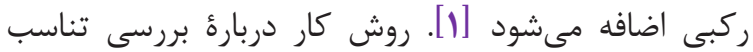

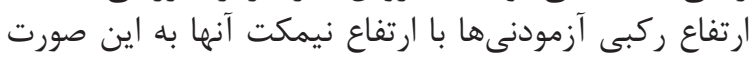

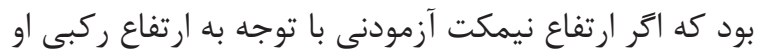

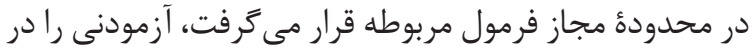

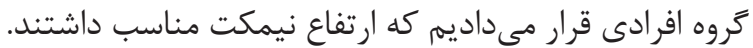

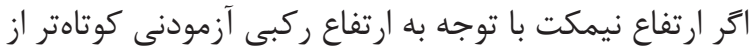

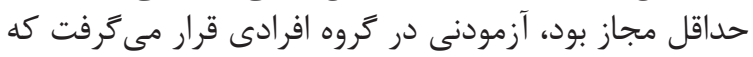

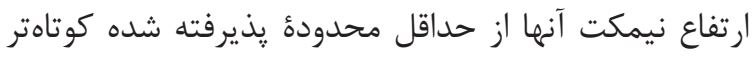

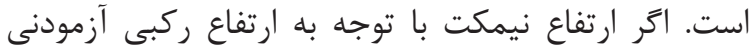

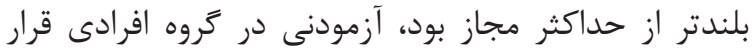

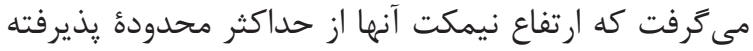

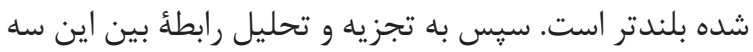

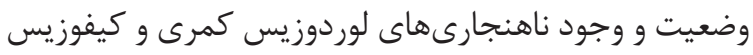

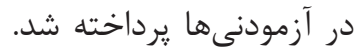

همجنين براى تشخيص تناسب اندازههاى آنترويومترى هر آزمودنى با ارتفاع ميز، از فرمول زير استفاده شد: تناسي اندازئ

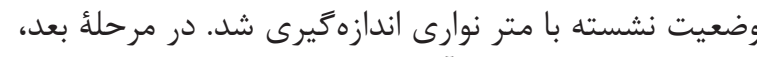

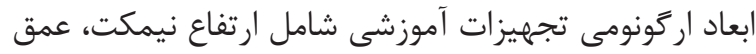

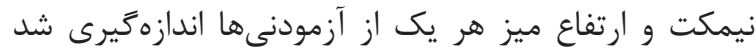

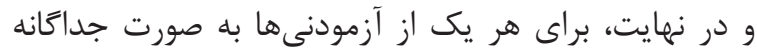

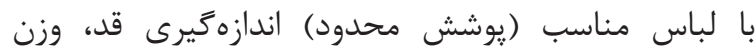

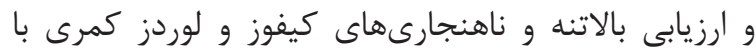

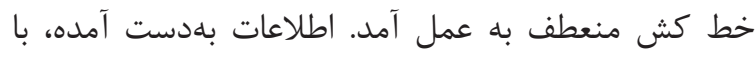

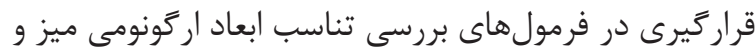

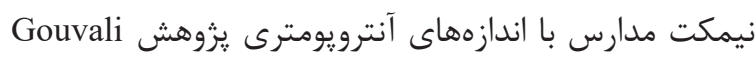

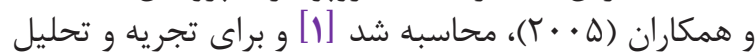

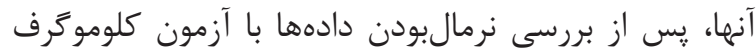

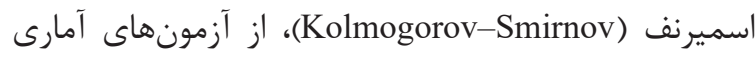
كاى اسكوئر (chi-square) در جداول توافقى دو طرفه و أناري ضريب همبستخى خطى نايارامترى فى كرامر (لramer) Correlation Coefficient-in Crosstabs) محاسبههاى آمارى به كمك نرمافزار Spss نسخة

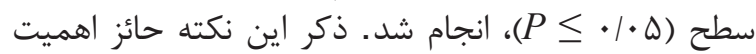

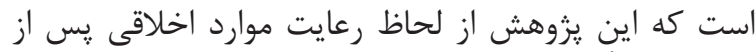

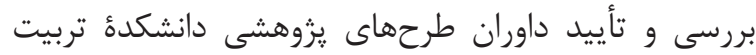

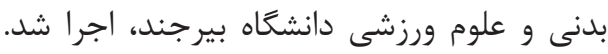

\section{خط كش منعطف}

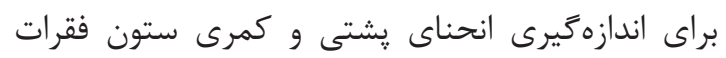

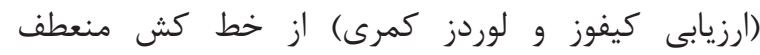

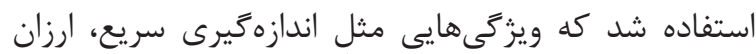

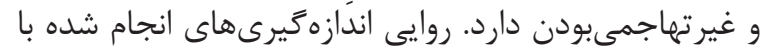

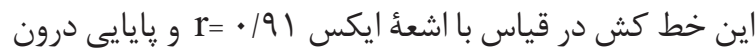

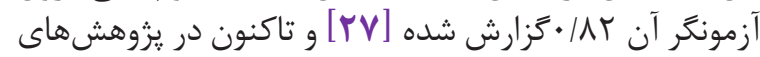

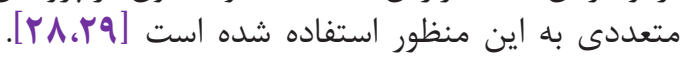

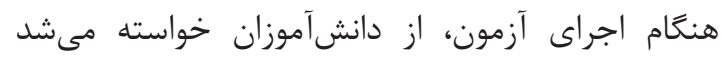

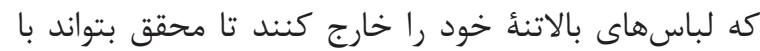

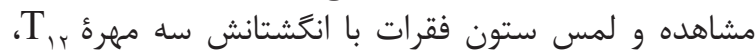

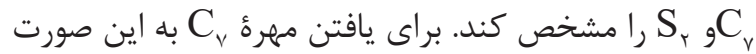

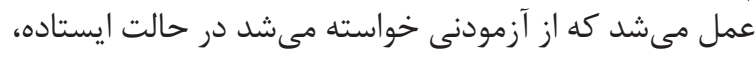

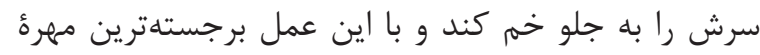

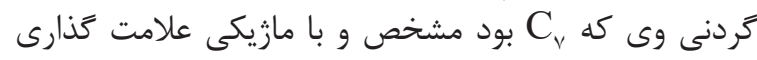

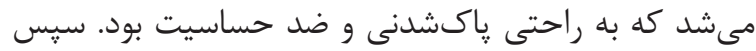

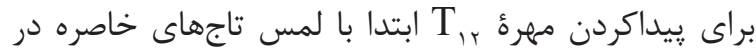

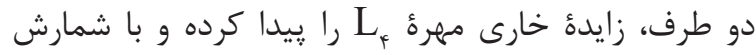

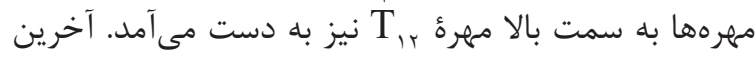

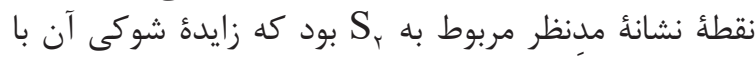

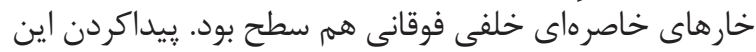

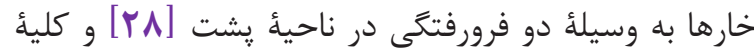

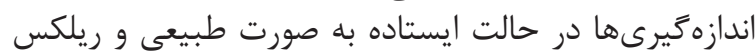

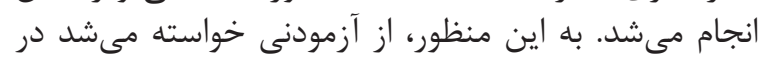

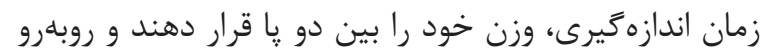

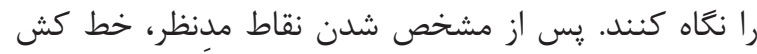

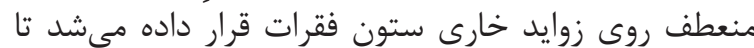


يرداخته شد.

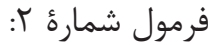

براى تشخيص تناسب عمق نيمكت هر آزمودنى با طول كفل ـ فضاى ركبى از فرمول زير استفاده شده است.

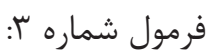

$$
0 / 80 \mathrm{~PB} \leq \mathrm{SD} \leq 0 / 95 \mathrm{~PB}
$$

در اين فرمول: PB طول كفل - فضاى ركبى Seat) عمق نشيمنكاه SD (length Popliteal-buttock)

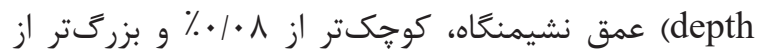

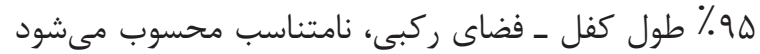

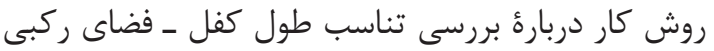

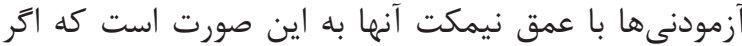

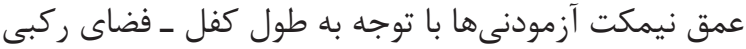

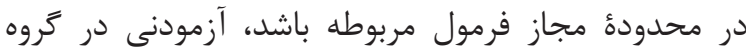

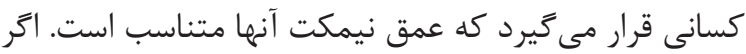

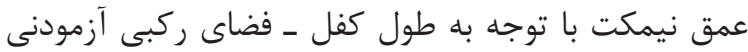

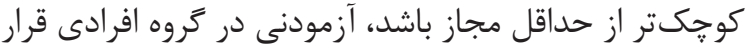

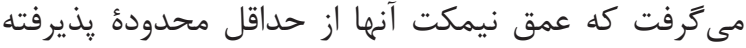

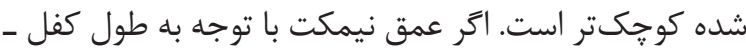

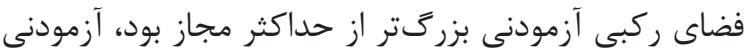

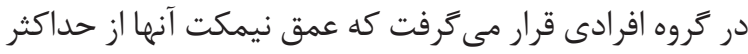

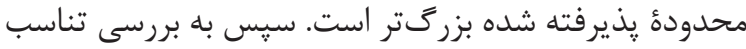

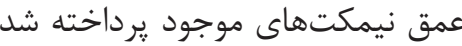

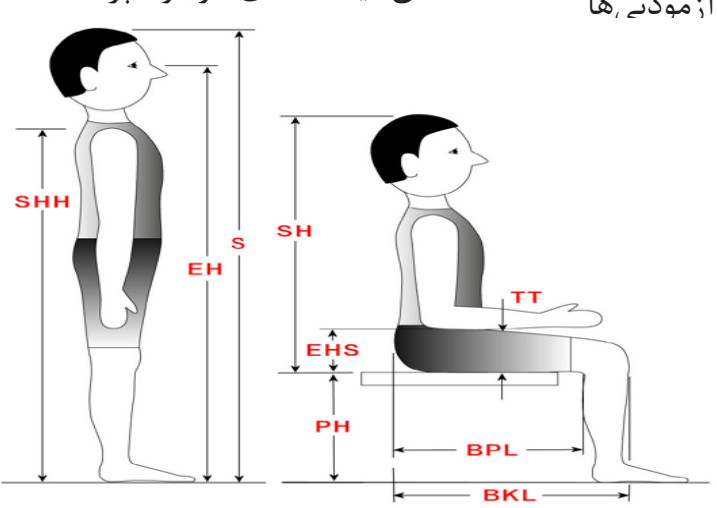

شكلا. متغيرهاى آنترويومتريكى انتخاب شده [1].
$\mathrm{E}+[(\mathrm{P}+2) \cos 30] \leq \mathrm{D} \leq[(\mathrm{P}+2) \cos 5]+(\mathrm{E} 0 / 8517)+(\mathrm{S} 0 / 1483)$

در اين فرمول: E ارتفاع آرنج •9 درجه تا سطح نشيمنحاه،

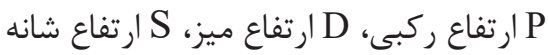

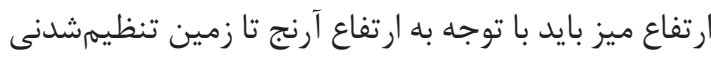

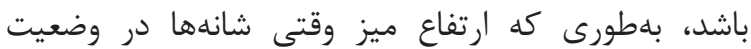

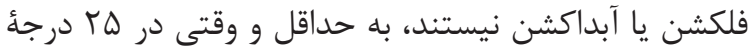

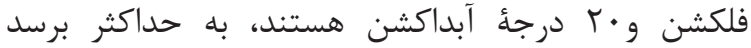

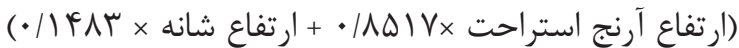

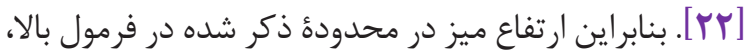

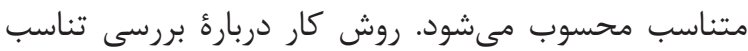

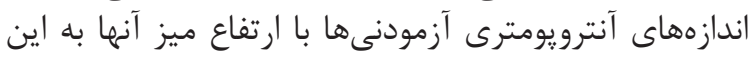

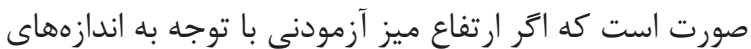

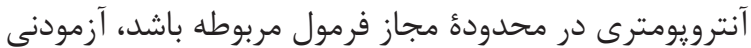

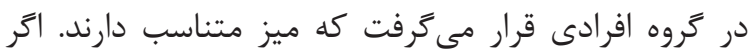

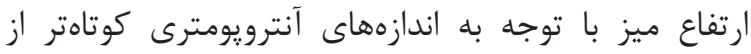

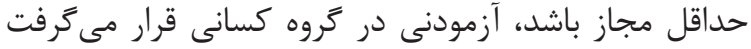

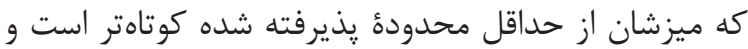

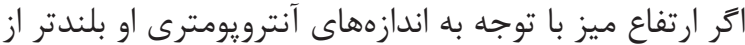

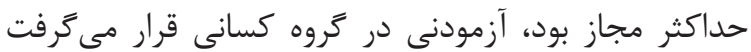

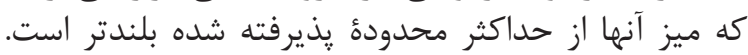

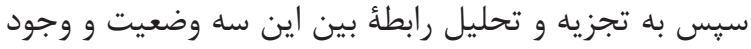

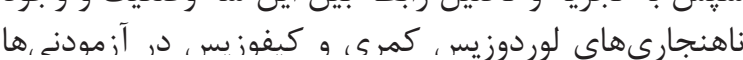

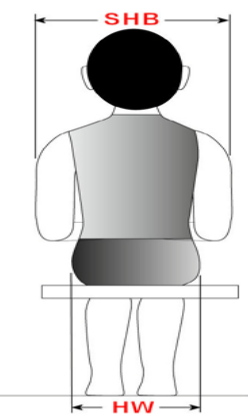

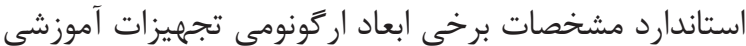

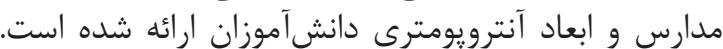

يافته ها اطلاعات مربوط به تناسب ابعاد اركونومى تجهيزات آموزشى آنقي

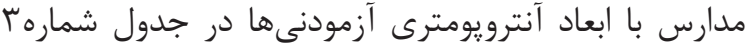

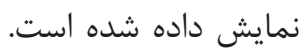
جدول زير نشان دهنده مشخصات دموگر افيك دانشآموزان بررسى شده است (جدول ( ).

\begin{tabular}{|c|c|c|}
\hline انحراف استاندارد & ميانگين & متغير \\
\hline .194 & $1.11 \mathrm{r}$ & سن \\
\hline$\Lambda / \Gamma \Lambda$ & Tr/gT & وزن \\
\hline V/G9 & $\mid F T / \Delta \Lambda$ & قد \\
\hline
\end{tabular}

جدول ا. مشخصات دموكر افيك دانش آموزان 
جدول ז. مشخصات برخى ابعاد اركونومى تجهيزات آموزشى مدارس و ابعاد آنترويومترى دانش آموزان

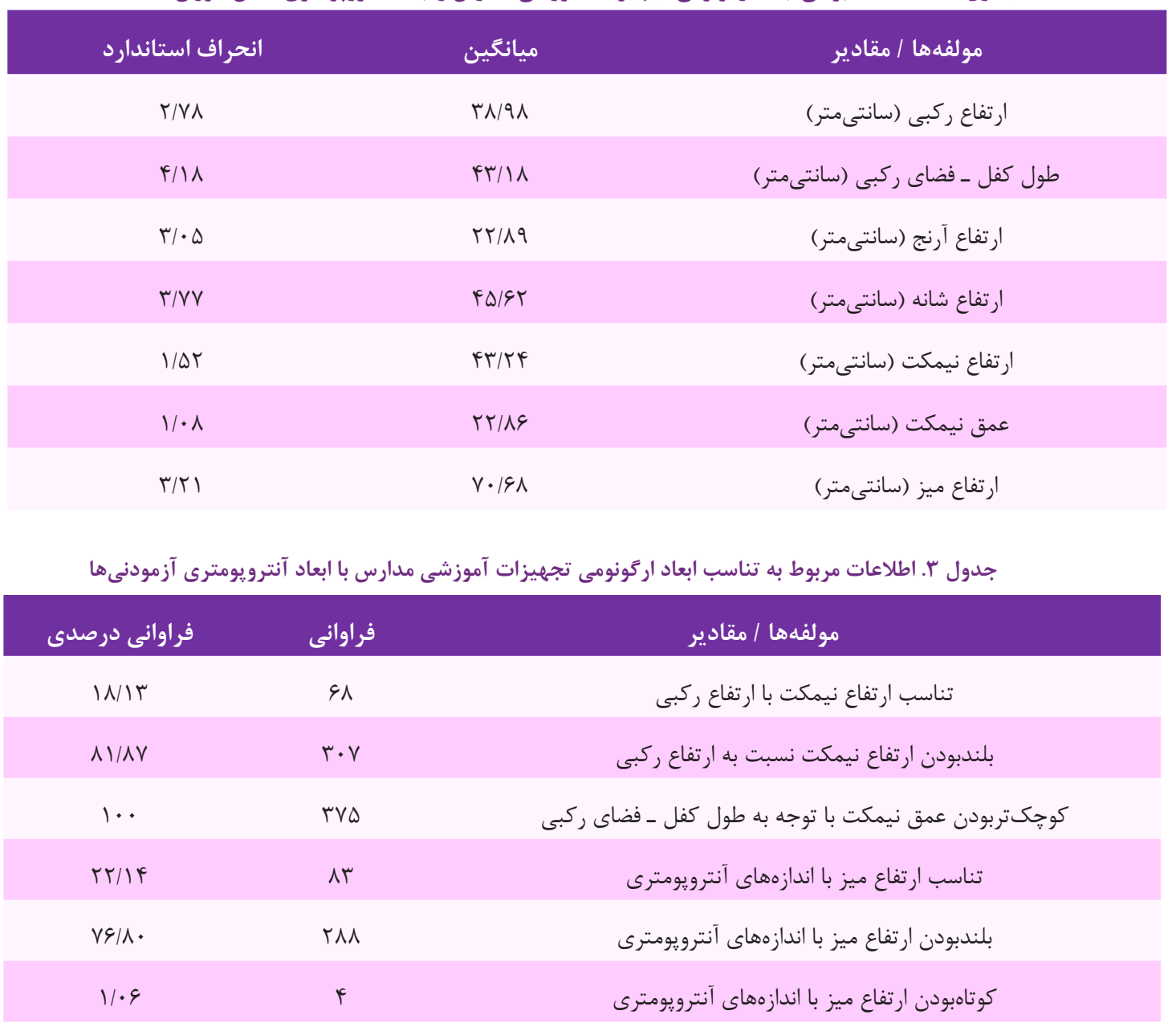

آزمودنىها از ميز متناسب با اندازههاى آنترويومترى خود استفاده مودى هنند.

در نمودار زير (نمودار (1)، فراوانى درصدى ناهنجارىهاى

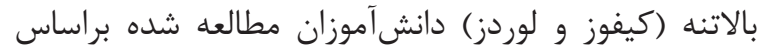
درصد، نمايش داده شده است.

همانطور كه در نمودار ارائه شده است درصد افراد مبتلا به ناهنجارى لوردز نسبت به كيفور بيشتر است.
همان طور كه در جدول ب نمايش داده شده است.

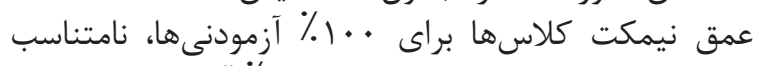

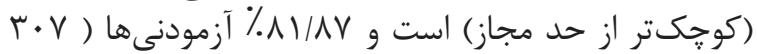

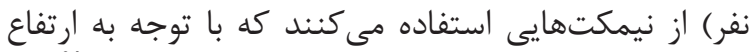

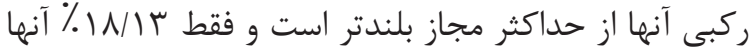

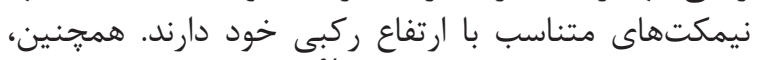

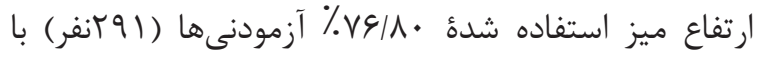

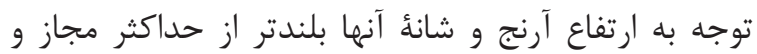

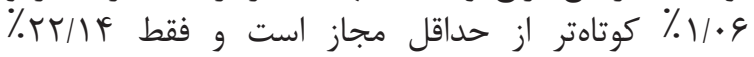

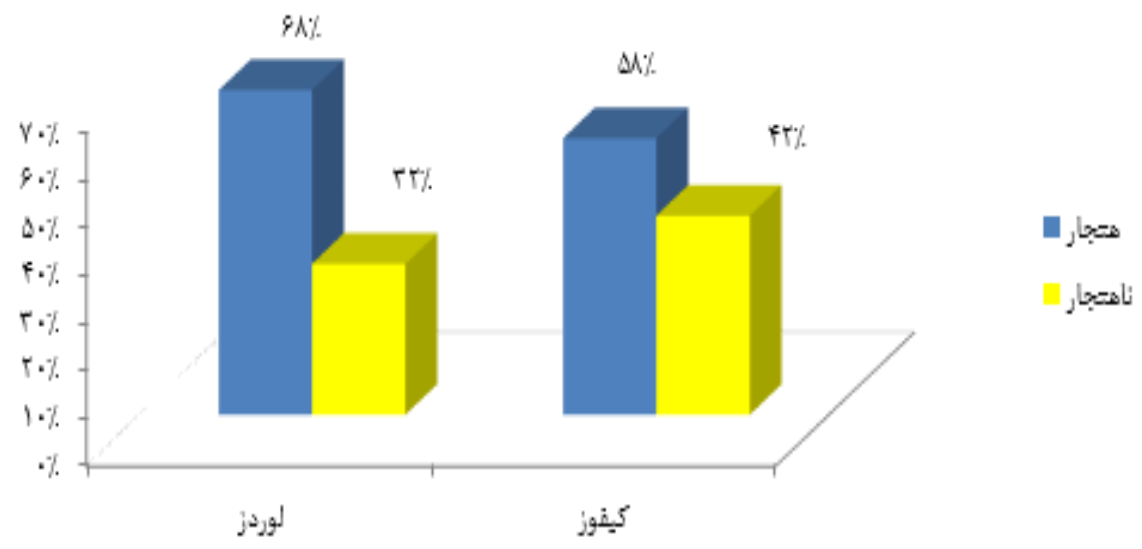

نمودار ا. فراوانى درصدى ناهنجارىهاى بالاتنه واحدهاى مطالعه شده 


$$
\text { كلاسترويا تناسب (ارتفاع آرنج و شانه) آزمودنى ها و ارتفاع ميزهاى }
$$

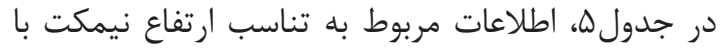

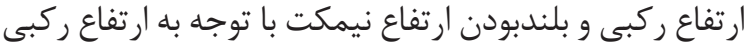
با ناهنجارى لوردوز و كيفوز نشان داده شده است.

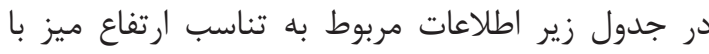

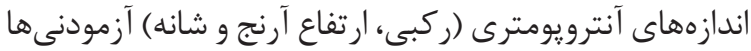

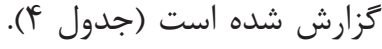

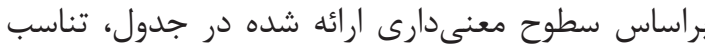

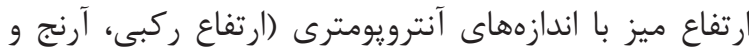

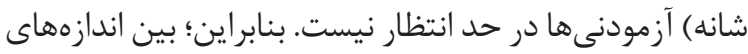

\begin{tabular}{|c|c|c|c|c|c|}
\hline سطح معنادارى & درجة آزادى & مقدار كاى اسكوئر & & ضعيت & \\
\hline$\cdot 1 \cdot .1$ & 1 & IDT/KY & $\begin{array}{l}9 \Lambda \\
r \cdot v\end{array}$ & متناسب & ركبى \\
\hline $.1 . .1$ & 1 & $\| \varepsilon / F A$ & $\begin{array}{l}\text { rar } \\
\text { rat }\end{array}$ & متناسب & آرنج و شانه \\
\hline
\end{tabular}

جدول F. اطلاعات مربوط به تناسب ار تفاع ميز با اندازههاى آنترويومترى (ركبى، ارتفاع آرنج و شانه) آزمودنىها

\begin{tabular}{|c|c|c|c|c|c|c|c|c|c|}
\hline $\begin{array}{l}3 \\
y \\
\frac{2}{5}\end{array}$ & 3 & $\hat{\frac{1}{3}}$ & $\begin{array}{l}\frac{a}{3} \\
\frac{3}{3} \\
y \\
y\end{array}$ & \multicolumn{2}{|c|}{ با توجده به ارتفاع ركبى نفي } & \multicolumn{2}{|c|}{ تناسب ار تفاع نيمكت } & وضعيت & ناهنجارىها \\
\hline \multirow{2}{*}{$\cdot 1 \cdot \cdot 1$} & \multirow{2}{*}{.$/ 1 T$} & \multirow{2}{*}{1} & \multirow{2}{*}{$9 / 1}$. & 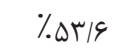 & $r \cdot 1$ & $\% 14 / 94$ & $\Delta \Delta$ & هنجار & \multirow[b]{2}{*}{ لوردوز } \\
\hline & & & & \% YA/TV & 1.9 & $\% r / \varphi v$ & r & ناهنجار & \\
\hline \multirow{2}{*}{.$/ \cdot r$. } & \multirow{2}{*}{.119} & \multirow[b]{2}{*}{1} & \multirow{2}{*}{$9 / V 1$} & \% FY/QT & $19 \mathrm{~V}$ & \% & $\Delta 1$ & هنجار & \multirow[b]{2}{*}{ كيفوز } \\
\hline & & & & \%rV/rr & If. & $\% \leftarrow / F \Delta$ & IV & ناهنجار & \\
\hline
\end{tabular}

جدوله، اطلاعات مربوط به تناسب ابعاد نيمكتها با ناهنجارى لوردوز و كيفوز

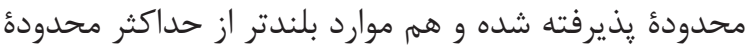

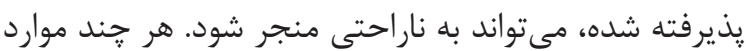

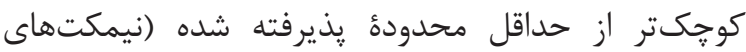

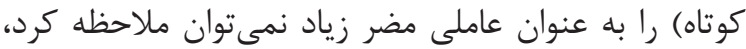

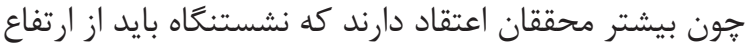

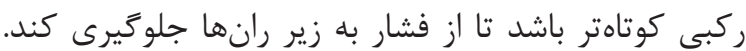

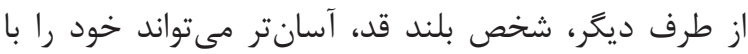

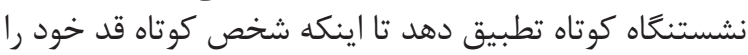

با نشستنحاه بلند تطبيق دهد [1]. ارتفاع صندلى بايد به اندازماى باشد كه مانع بارئ واردشدن

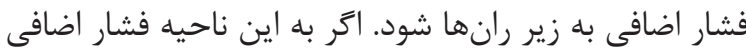

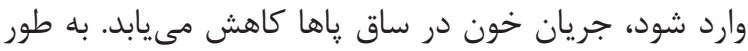

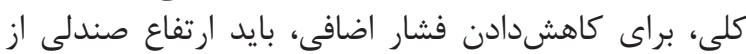

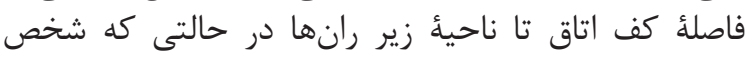

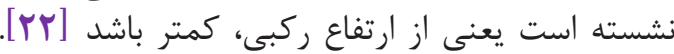

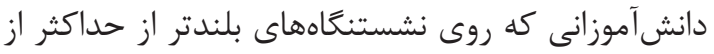

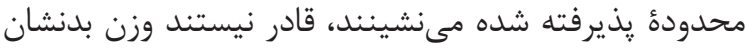

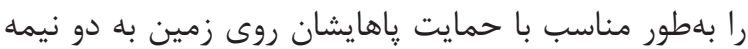

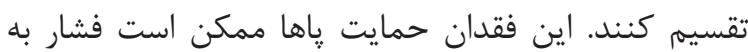
بافتهاى محدودة خلفى زانو را افزايش دهد انها

نتايج اين بخش از يزوهش با نتايج يزوهشهاى Gouvali

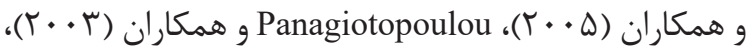

آزمون كاى اسكوئر نشان مى دهد كه رابطؤ معنادارى بين

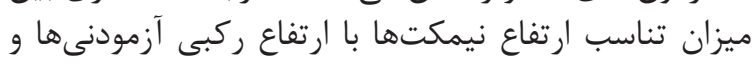

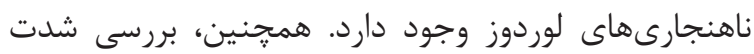

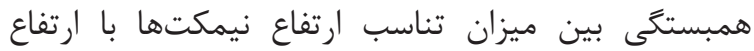

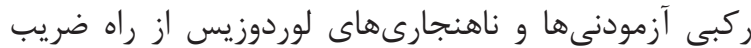

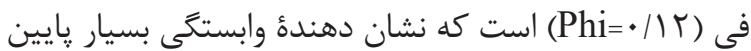
اين دو متغير است.

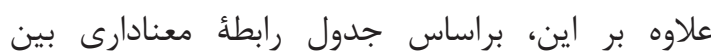

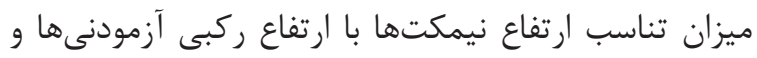

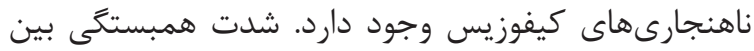

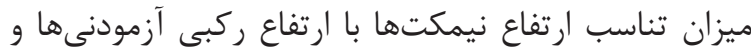

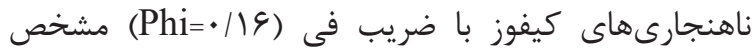

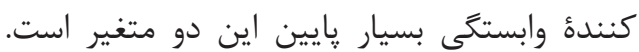

\section{بحث}

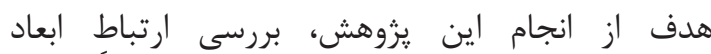

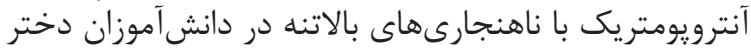

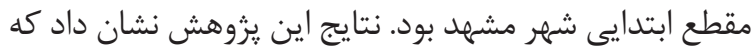

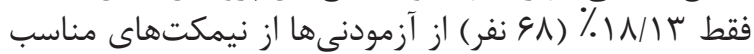

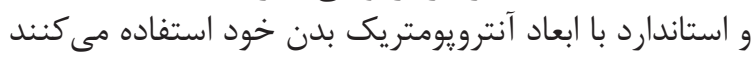

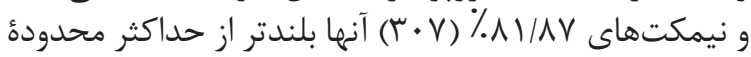
يذيرفته شده است.

دربارة ارتفاع نشستنگاه، هم موارد كوجگتر از حداقل 


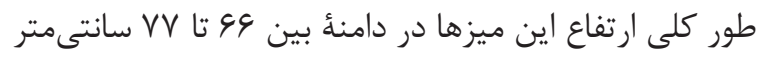

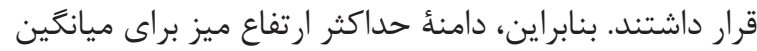

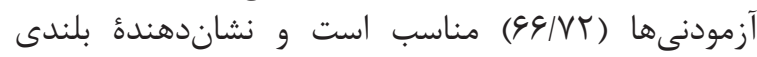

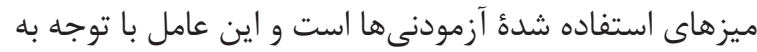

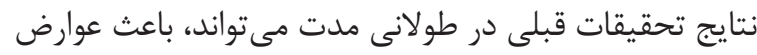

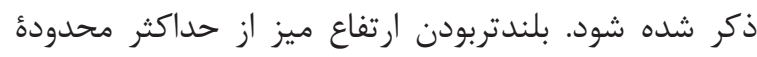

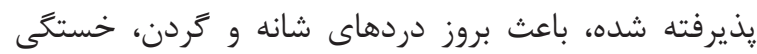

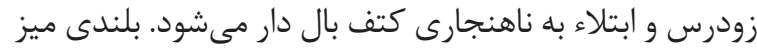

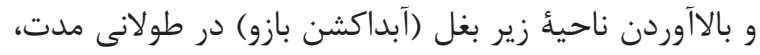

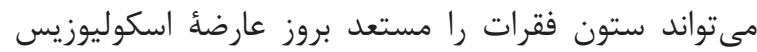
بكند [V]

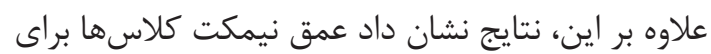

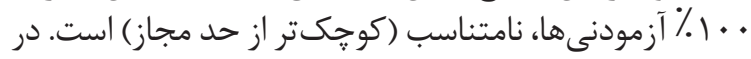

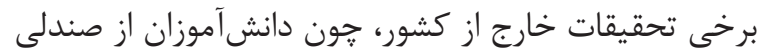

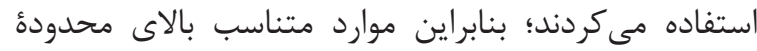

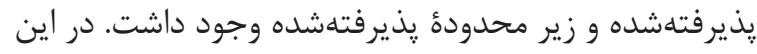

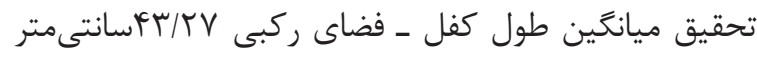

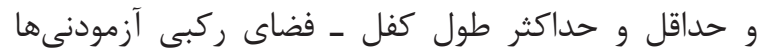

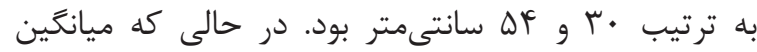

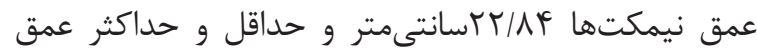

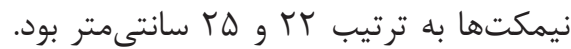

با توجه به فرمول تعيين تناسب عمق نيمكت و ورئ

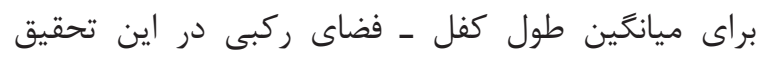

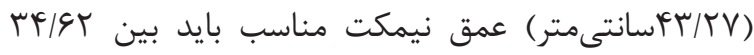

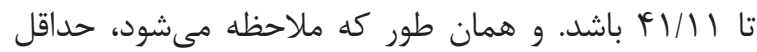

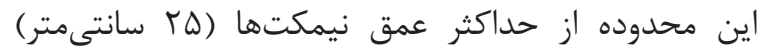

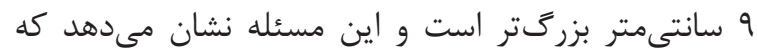

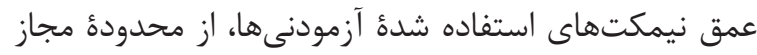

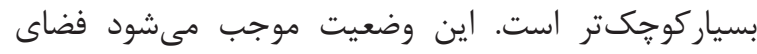

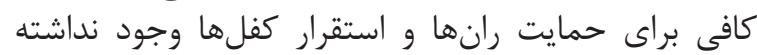

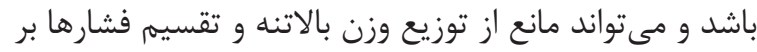

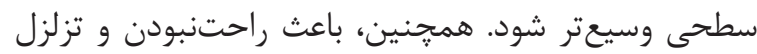

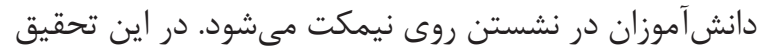

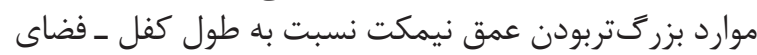

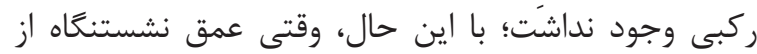

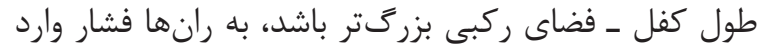

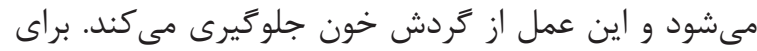

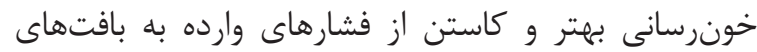

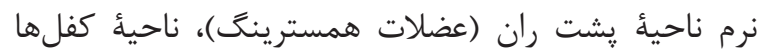

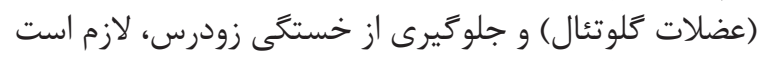

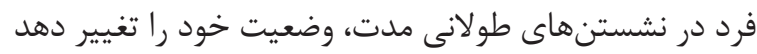

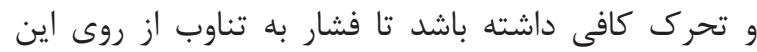

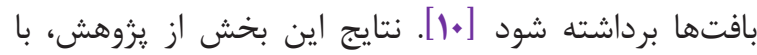

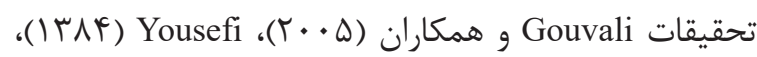
Agharafiee

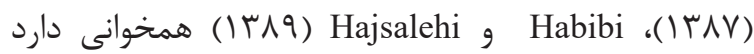
[1.19.1V.19.4.]

اين يزوهش، علاوه بر موارد فوق، نشان داد كه بين ميزان

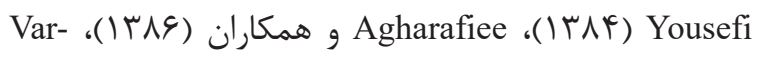
Mazyar

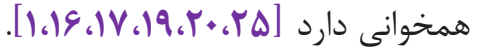

Panagiotopoulou

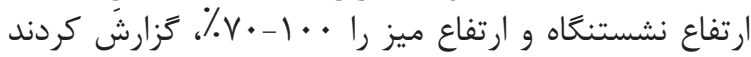

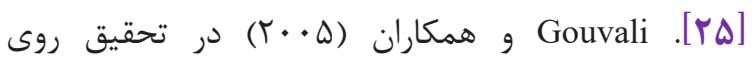

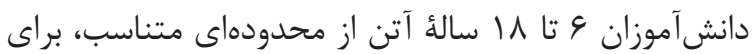

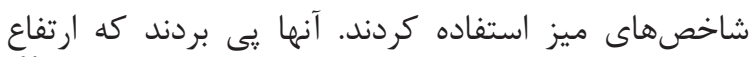

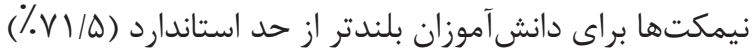

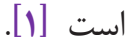

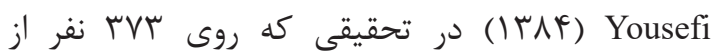
دانشآموزان پسر سه مقطع تحصيلى شهرستان كرمانشاه

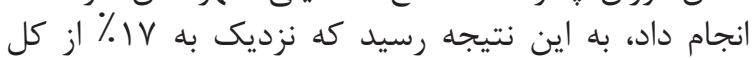

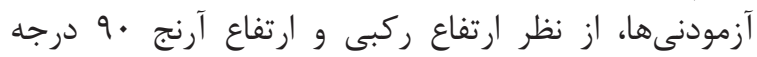

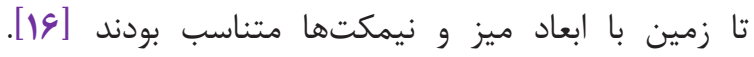
r.. Hajsalehi و Habibi

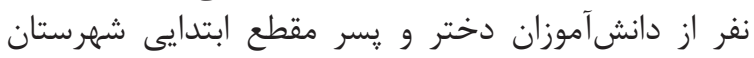

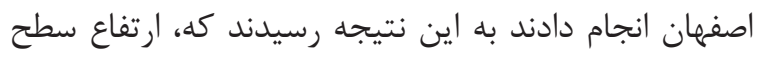

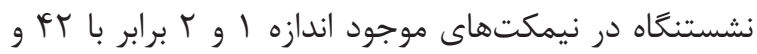

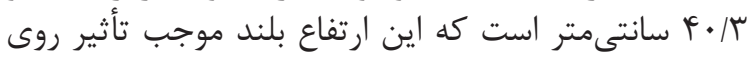

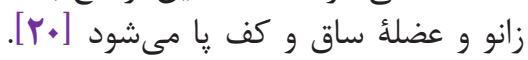

Varmazyar

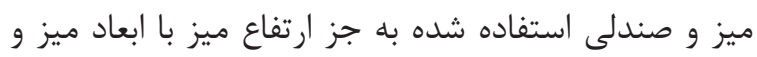

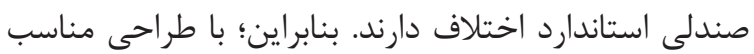

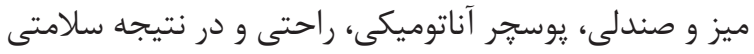

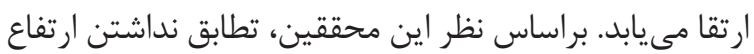

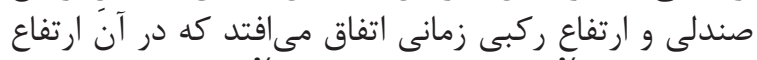

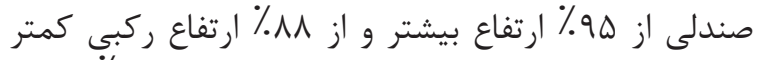

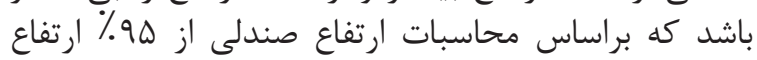

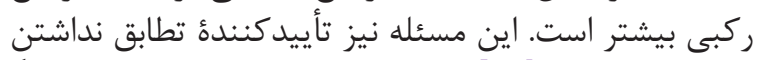

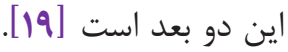

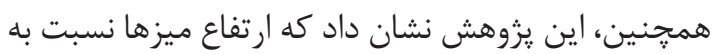

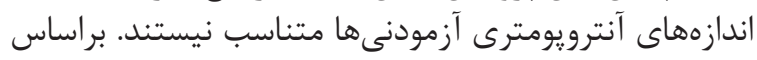

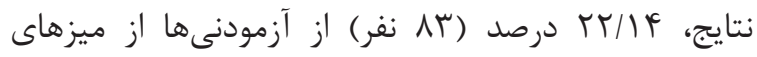

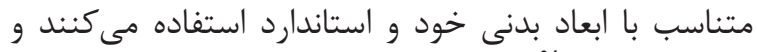

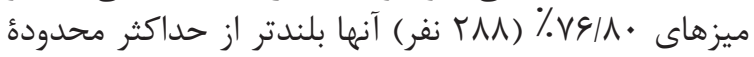

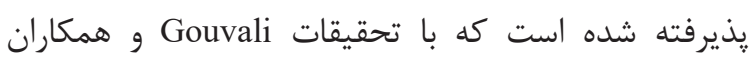

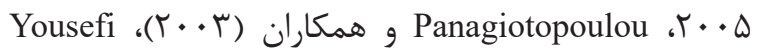

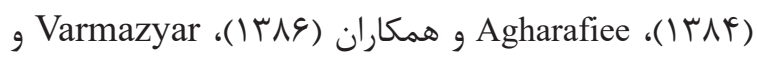

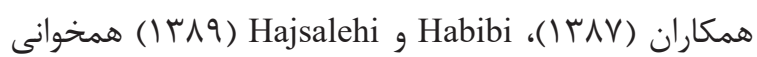

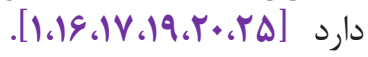

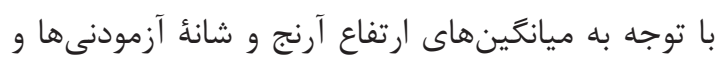

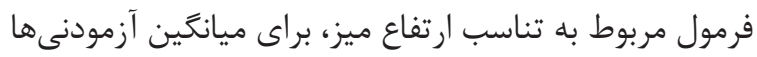

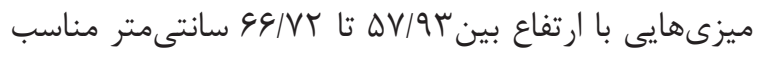

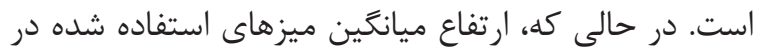

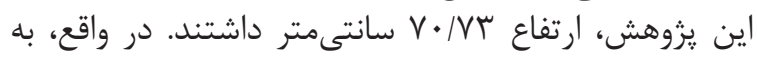


بنابراين به منظور جلوگيرى از وضعيتهاى بدنى نامناسب،

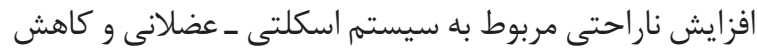

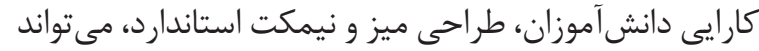

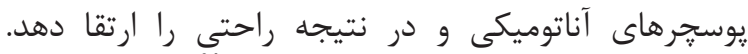

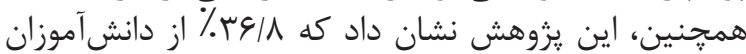

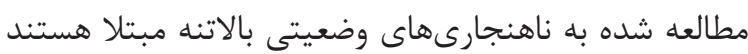

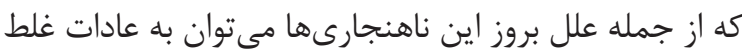

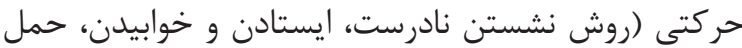

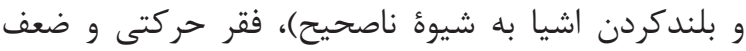

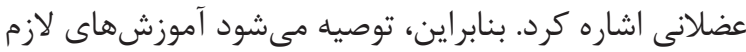

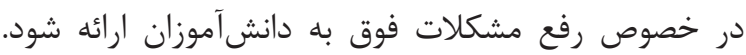

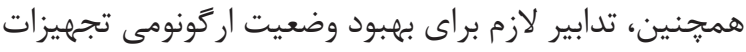

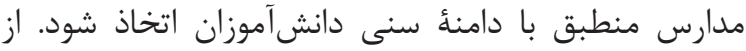

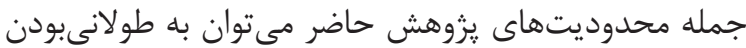

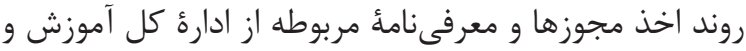

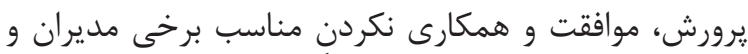

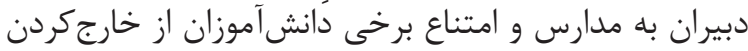

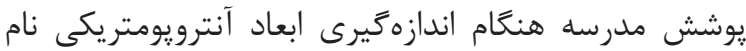
برد.

$$
\text { سياسگزارى }
$$

بدين وسيله از تمام كسانى كه ما را در انجام اين يثرهش

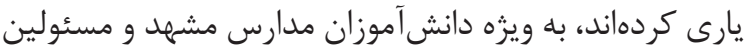

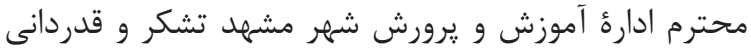

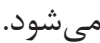

\section{تعارض منافع}

بين نويسند

\section{References}

1. Gouvali MK, Boudolos K. Match between school furniture dimensions and children's Anthropometry. Appl Ergon. 2006;37(6):765-73. https://doi.org/10.1016/j.apergo.2005.11.009 PMID: 16442494

2. Mirbagheri SS, Mortazavi SS, Rahmani Rasa A, Hossein Alizadeh J. Relationship between spinal abnormalities and musculoskeletal pains in university students in Hamadan, Iran. J Res Rehabil Sci. 2013;9(3):515-24. http://www.sid.ir/En/ Journal/ViewPaper.aspx?ID=377495

3. Guite JW, Logan DE, Sherry DD, Rose JB. Adolescent self-perception: associations with chronic musculoskeletal pain and functional disability. J Pain. 2007;8(5):379-86. https://doi.org/10.1016/j. jpain.2006.10.006 PMID: $\underline{17275417}$

4. Waersted M, Hanvold TN, Veiersted KB. Computer work and musculoskeletal disorders of the neck and upper extremity: a systematic review. BMC Musculoskelet Disord. 2010;11(1):79. https://doi.org/10.1186/1471-2474-11-79
تناسب ارتفاع نيمكتها با ارتفاع ركبى آزمودنىها و ناهنجارى

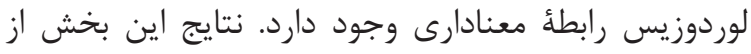

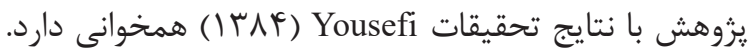

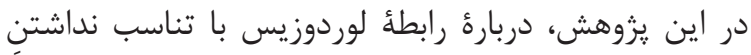

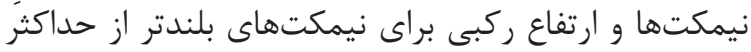

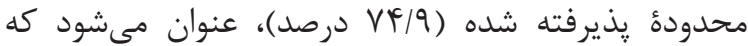

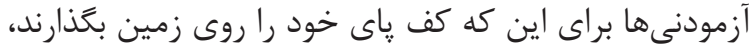

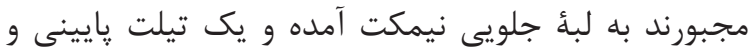

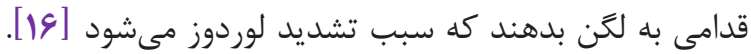
همجنين، نتايج يثوهش حاضر نشان داد كه بين ميزان

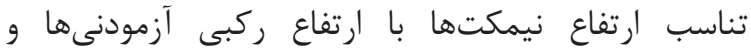

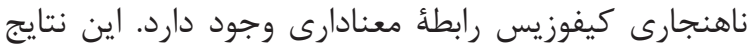

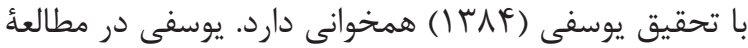

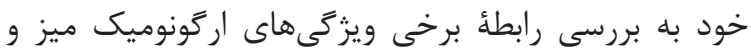

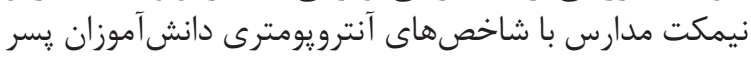

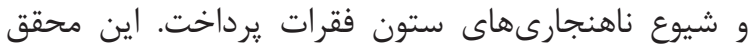

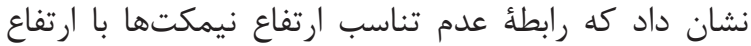

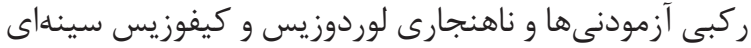

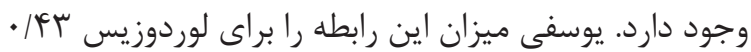

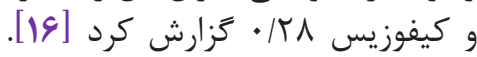

$$
\text { نتيجه كيرى }
$$

براساس نتايج يزوهش حاضر، جنين به نظر مى ميرسد كه

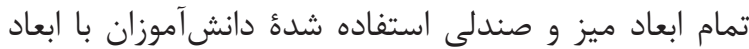

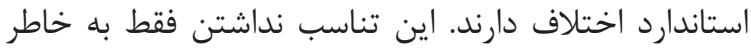

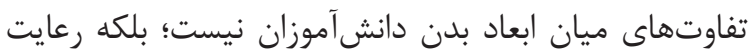

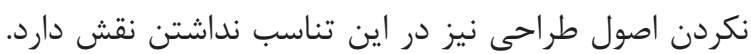

\section{PMID:20429925 PMCID:PMC2874766}

5. Murphy S, Buckle P, Stubbs D. Classroom posture and self-reported back and neck pain in schoolchildren. Appl Ergon. 2004;35(2):113-20. $\quad$ https://doi.org/10.1016/j. apergo.2004.01.001 PMID: 15105072

6. Ilbeigi S, Kabootari A, Afzalpour M, Farzaneh H. The Relationship between Sitting Posture and Musculoskeletal Pain in Boy Elementary School Students. J Ergon. 2018;5(3):41-9. http://journal. iehfs.ir/article-1-473-en.html

7. Dianat I, Alipour A, Asgari Jafarabadi M. Risk factors for neck and shoulder pain among schoolchildren and adolescents. J Paediatr Child Health. 2018;54(1):20-7. https://doi.org/10.1111/ jpc.13657 PMID:28782292

8. Dianat I, Alipour A, Asghari Jafarabadi M. Prevalence and risk factors of low back pain among school age children in Iran. Health Promot Perspect. 2017;7(4):223-9. https://doi.org/10.15171/ $\underline{\text { hpp.2017.39 }}$ PMID:29085800 PMCID:P- 
9. Caneiro JP, O'Sullivan P, Burnett A, Barach A, O'Neil D, Tveit O, Olafsdottir K. The influence of different sitting postures on head/neck posture and muscle activity. Man Ther. 2010;15(1):5460. https://doi.org/10.1016/j.math.2009.06.002 PMID: 19643658

10. Prins Y, Crous L, Louw QA. A systematic review of posture and psychosocial factors as contributors to upper quadrant musculoskeletal pain in children and adolescents. Physiother Theory Pract. 2008;24(4):221-42. https://doi.org/10.1080/09593980701704089 PMID: 18574749

11. Murphy S, Buckle P, Stubbs D. Classroom posture and self-reported back and neck pain in schoolchildren. Appl Ergon. 2004;35(2):113-20. https://doi.org/10.1016/j.apergo.2004.01.001 PMID: 15105072

12. Ilbeigi S, Biglar A, Saghebjoo M, Farzaneh $H$. The investigation of relationship between work-related musculoskeletal disorders and level of physical activity and body posture of dentists in Mashhad city in 2012-2013. J Torbat Heydariyeh Univ Med Scie. 2014;2(4):31-7. http://www. sid.ir/En/Journal/ViewPaper.aspx?ID=513186

13. Mououdi M A, Mousavinasab S N, Gramian S M R, Akbari J. Anthropometric Evaluation of Primary School Students in the Mazandaran Province for the Design of School Furniture . J Ergon. 2016;4(1):47-55. https://doi.org/10.21859/joe$\underline{04016}$

14. Heidarimoghadam R, Motamedzade M, Roshanaei G, Ahmadi R. Match between school furniture dimensions and children's anthropometric dimentions in male elementary schools. J Ergonom. 2014;2(1):9-18. http://journal.iehfs.ir/ article-1-58-en.html

15. Heidarimoghadam R, Golmohammadi R, Roshanaei G, Zare R. Assessing the match between female primary students' anthropometric dimensions and furniture dimensions in Hamadan schools in 2013. J Health Safe Work. 2015;5(1):47-56. http://jhsw.tums.ac.ir/article-15242-en.html

16. Yousefi B. The relationship between some characteristics of ergonomic desks and chairs of schools with anthropometric indices of male students of Kermanshah city and abnormalities of the spine and musculoskeletal upper limb. Harakat. 2006;26:23-40.

17. Agharafiee A, Parsapajouh D, Khanjazani R, Ebrahimi G, Khodadadeh Y. Evaluation of mismatch between school furniture dimentions and students anthropometric characteristics in Karaj primary schools, Iran. J Iran Natural Res. 2008;61(3):693-711. http://www.sid.ir/En/Jour- $\underline{\text { nal/ViewPaper.aspx?ID }=138479}$

18. Dianat I, Karimi MA, Asl Hashemi A, Bahrampour S. Classroom furniture and anthropometric characteristics of Iranian high school students: proposed dimensions based on anthropometric data. Appl Ergon. 2013;44(1):101-8. https://doi.org/10.1016/j.apergo.2012.05.004 PMID:22695080

19. Varmazyar S, Ghalehnovi M, Amani Z, Mohammadi F, Aivazloo T, Inanloo F et al . School Desk and Chair Design Based on High School Female Students Anthropometry Qazvin, Iran 2007 to 2008. Qom Univ Med Sci J . 2008;2(3):39-46. http://journal.muq.ac.ir/article-1-679-en.html

20. Habibi E, Hajsalehi E. Anthropometric assessment for designing primary school classroom desk and bench size. J Health Sys Res. 2011;6(2):186-93.

21. Castellucci HI, Arezes PM, Viviani CA. Mismatch between classroom furniture and anthropometric measures in Chilean schools. Appl Ergon. 2010;41(4):563-8. https://doi.org/10.1016/j. apergo.2009.12.001 PMID:20031115

22. Parcells C, Stommel M, Hubbard RP. Mismatch of classroom furniture and student body dimensions: empirical findings and health implications. J Adolesc Health. 1999;24(4):265-73. https:// doi.org/10.1016/S1054-139X(98)00113-X

23. Diep NB. Evaluation of fitness between school furniture and children body size in two primary schools in Haiphong, Vietnam [dissertation]. Luleå Sweden: Lulea University of Technology. 2003;12(3):11-23.

24. Milanese S, Grimmer K. School furniture and the user population: an anthropometric perspective. Ergonomics. 2004;47(4):416-26. https://doi.org/10.1080/0014013032000157841 PMID: 14680998

25. Panagiotopoulou G, Christoulas K, Papanckolaou A, Mandroukas K. Classroom furniture dimensions and anthropometric measures in primary school. Appl Ergon. 2004;35(2):1218. https://doi.org/10.1016/j.apergo.2003.11.002 PMID: $\underline{15105073}$

26. Oyewole SA, Haight JM, Freivalds A. The ergonomic design of classroom furniture/computer work station for first graders in the elementary school. Int J Ind Ergon. 2010;40(4):437-47. https://doi.org/10.1016/j.ergon.2010.02.002

27. Ghorbani L, Ghasemi G. Effects of Eight Weeks Corrective Exercises on Lumbar Lordosis. Research in Rehabilitation Sciences. 2007;3(2):5971. http://jrrs.mui.ac.ir/index.php/jrrs/article/ view/88 
28. Daneshmandi H, Sardar Ma, Taghizadeh M. The effect of exercises program on lumbar lordosis. Research on Sport Science. 2005;3(8):91-103. http://www.sid.ir/En/Journal/ViewPaper.aspx$?$ ID $=87740$
29. BayatTorq M, SarafrazArdakani H, Mazidi M, Savadi M, Rafati S. Prevalence of low back pain in school-age children and associated risk factors. Bimonthly Journal of Hormozgan University of Medical Sciences. 2013;16(6):477-83. hmj. hums.ac.ir/article-1-847-en.pdf 